\title{
A randomized controlled trial of preprocedure administration of parecoxib for therapeutic endoscopic retrograde cholangiopancreatography
}

This article was published in the following Dove Press journal:

Journal of Pain Research

I August 2012

Number of times this article has been viewed

\author{
Somchai Amornyotin \\ Wiyada Chalayonnawin \\ Siriporn Kongphlay \\ Department of Anesthesiology and \\ Siriraj GI Endoscopy Center, Faculty \\ of Medicine Siriraj Hospital, Mahidol \\ University, Bangkok, Thailand
}

Introduction: Parecoxib is occasionally used for analgesia in postprocedural patients. The clinical efficacy of parecoxib used for endoscopic retrograde cholangiopancreatography (ERCP) is controversial. The aim of the study was to determine the clinical efficacy of preprocedure administration of parecoxib for therapeutic ERCP patients.

Methods: Eighty-five patients who underwent therapeutic ERCP in a single year were randomly assigned to normal saline group $(C, n=43)$ and parecoxib group $(P, n=42)$. Patients in group $\mathrm{C}$ received normal saline and those in group $\mathrm{P}$ received $40 \mathrm{mg}$ of parecoxib intravenously in equivalent volume. Patients in both groups received the saline or parecoxib 60 seconds before administration of the sedative agents. All patients were monitored for the depth of sedation by using the Narcotrend ${ }^{\mathrm{TM}}$ monitor, maintaining stage D0-E0 during ERCP. All patients were oxygenated with $100 \% \mathrm{O}_{2}$ via nasal cannula and sedated with $0.03 \mathrm{mg} / \mathrm{kg}$ of intravenous midazolam and $1 \mu \mathrm{g} / \mathrm{kg}$ of intravenous fentanyl as well as the titration of intravenous propofol. After the ERCP procedure, pethidine in an intramuscular dose of $0.5-1.0 \mathrm{mg} / \mathrm{kg}$ was used as rescue medication. The pain scores (visual analog scale [VAS], 0-10) at 2, 12, and 24 hours post-ERCP, the total number of doses of pethidine used, the dose volume of pethidine used, patient satisfaction, endoscopist satisfaction, and complications were recorded.

Results: There were no significant differences in sedative and analgesic agents used during the procedure, pain at 24 hours post-ERCP, endoscopist satisfaction, and complications in both groups. The total number of doses of pethidine used post-ERCP in group $\mathrm{C}$ was significantly higher than in group P. Additionally, the mean pain score at 2 and 12 hours post-ERCP in group $\mathrm{C}$ was significantly greater than in group P. Patient satisfaction in group $\mathrm{P}$ was higher than in group C.

Conclusion: Preprocedure administration of parecoxib for therapeutic ERCP patients was clinically effective. The analgesic efficacy of a standard dose of parecoxib was clearly demonstrated during the first 12 hours postprocedure. Additionally, patient satisfaction in the parecoxib group was also higher than in the control group.

Keywords: parecoxib, endoscopic retrograde cholangiopancreatography, clinical efficacy, preprocedure

\section{Introduction}

Postprocedural pain is predictable and prevention of this pain is a better management strategy than treating the pain once it has occurred. ${ }^{1}$ Endoscopic retrograde cholangiopancreatography (ERCP) is an invasive procedure and produces moderateto-severe pain. ${ }^{2}$ It is commonly used for diagnosis and treatment of pancreatobiliary abnormalities. ${ }^{3,4}$ Postoperative pain may affect recovery including hospital stay, feeding,
Correspondence: Somchai Amornyotin of Medicine Siriraj Hospital, Mahidol University, Bangkok, 10700, Thailand

Tel +6624197990

Fax $+66241 I 3256$

Email somchai.amo@mahidol.ac.th 
and delay in starting work. Therefore, the administration of pain medication would be necessary.

Opioids, local anesthetics, and nonsteroidal antiinflammatory drugs (NSAID) can be used to manage moderate-to-severe acute pain. ${ }^{5}$ Conventional NSAIDs inhibit the cyclooxygenase (COX) enzymes and, therefore, produce an anti-inflammatory and analgesic effect. The COX-1 isoenzyme plays a key role in the physiological prostaglandin synthesis in the gastric mucosa, platelets, and kidney. ${ }^{6}$ Cox-2 induction has been shown to be associated with pathophysiological stimuli, specifically injury and inflammation. Coxibs are the newer NSAIDs, which specifically inhibit the COX-2 isoenzyme to provide the anti-inflammatory and analgesic effects. ${ }^{7}$ Parecoxib is an injectable prodrug of valdecoxib, which is a potent and selective inhibitor of COX-2. ${ }^{8}$ The analgesic efficacy of parecoxib has been demonstrated after third molar extraction, ${ }^{8}$ gynecological, ${ }^{8,9}$ and orthopedic surgeries. ${ }^{8,10}$

Currently there have been no reports on the efficacy of parecoxib after the ERCP procedure. This is the first study evaluating the postprocedure analgesic efficacy of a single dose of parecoxib administered prior to the ERCP procedure. The aim of this study was to determine the clinical efficacy of preprocedure administration of parecoxib for therapeutic ERCP patients. The study was designed to test the null hypothesis that procedural pain after the therapeutic ERCP procedure in the parecoxib group would be lower than the placebo group.

\section{Methods}

\section{Patients}

A total of 85 consecutive patients from a tertiary care teaching hospital in Thailand were recruited for the study. These patients were 18-90 years of age and underwent therapeutic ERCP procedures. Exclusion criteria included any clinical evidence of severe liver diseases according to the American Society of Anesthesiologists (ASA) physical status of classes IV or V. The study was approved by the Institutional Review Board of the Faculty of Medicine, Siriraj Hospital. All the enrolled patients provided written informed consent to undergo the procedures and to participate in the study.

\section{Study design}

The study was a single-dose, randomized, blind, and placebo-controlled clinical trial. Eighty-five patients who underwent therapeutic ERCP in a single year, were randomly assigned to either the parecoxib group $(\mathrm{P} ; \mathrm{n}=42)$ or the normal saline group $(\mathrm{C} ; \mathrm{n}=43)$. In group $\mathrm{P}$, a $40 \mathrm{mg}$ dose of parecoxib (Dynastat; Pfizer Inc, New York, NY) was given intravenously 60 seconds before sedative agents were administered. In group $\mathrm{C}$, an equivalent volume of normal saline was given intravenously 60 seconds before sedative agents were administered. The primary outcome variable of the study was the post-procedural pain after the therapeutic ERCP procedure. The secondary outcome variables were the total number of doses of pethidine used post-ERCP, the dose volume of pethidine used post-ERCP, patient satisfaction, endoscopist satisfaction, and complications during and immediately after procedure. Procedural pain was compared by using a visual analog scale score (VAS; 0-10).

\section{Sedation procedure}

All patients were oxygenated with $100 \% \mathrm{O}_{2}$ via nasal cannula and sedated with $0.03 \mathrm{mg} / \mathrm{kg}$ of intravenous midazolam and $1 \mu \mathrm{g} / \mathrm{kg}$ of intravenous fentanyl as well as the titration of intravenous propofol. No other medications were administered before the procedure. All sedated patients were sedated to a deep sedation level, in accordance with guidelines of the American Society of Anesthesiologists. ${ }^{11}$ Each patient's level of sedation was assessed by the Narcotrend ${ }^{\mathrm{TM}}$ monitor and maintained at D0-E0, which indicates a deep level. If the depth of sedation was too light, a bolus dose of propofol (10-20 mg) was administered until the desired stage of the Narcotrend ${ }^{\mathrm{TM}}$ monitor was reached. After the ERCP procedure, pethidine in an intramuscular dose of $0.5-1.0 \mathrm{mg} / \mathrm{kg}$ was used as rescue medication. Sedation was administered by the residents in anesthesiology and the nurse anesthetists under the supervision of a certified anesthesiologist. The anesthetic personnel were blinded to the randomization procedure. Each patient was monitored with noninvasive blood pressure, heart rate, electrocardiogram, oxygen saturation, and Narcotrend ${ }^{\mathrm{TM}}$ monitoring. ${ }^{12}$ Patients' vital signs were monitored and recorded by the blinded nurse anesthetist or anesthesiology resident.

\section{ERCP procedure}

The ERCP procedure was done by using an Olympus video duodenoscope (TJF 160 R; Olympus Corporation, Tokyo, Japan). The endoscopists were three staff endoscopists who had experience of more than ten years. The procedure was performed with the patient in either the prone or left lateral position.

\section{Pain assessment}

Before administration of any sedative and analgesic drugs, patients rated their pre-procedure pain on a $0-10 \mathrm{~mm}$ VAS, 
where $0 \mathrm{~mm}$ is no pain and $10 \mathrm{~mm}$ is the worst imaginable pain. After the procedure, patients were moved to the recovery room, where they were monitored for the next 2 hours. The anesthetic personnel that were blinded to the procedure interviewed the patient with a questionnaire evaluating the procedural pain and the patient's satisfaction at 24 hours postprocedure. The procedural pain at 2, 12, and 24 hours post-ERCP was evaluated by the VAS. Patient satisfaction was categorized as: 1 , very satisfied; 2 , satisfied; 3 , neutral; and 4 , unsatisfied.

The complications during and immediately after the procedure were recorded. Changes in hemodynamic variables such as hypertension or hypotension (increase or decrease in blood pressure by $20 \%$ from baseline), tachycardia or bradycardia (increase or decrease in heart rate by $20 \%$ from baseline), and oxygen desaturation $\left(\mathrm{SpO}_{2}<90 \%\right)$ were recorded. In addition, upper airway obstruction and nausea or vomiting was also recorded as a complication.

\section{Endoscopist assessment}

The endoscopist carrying out the procedure was blinded to the randomization method. Immediately after the procedure, the endoscopist was asked to rank his/her satisfaction of the procedure. The endoscopist's satisfaction for the procedure was ranked as follows: 1 , very satisfied; 2 , satisfied; 3 , neutral; and 4, unsatisfied.

\section{Statistical analysis}

To detect a difference in the procedural pain after therapeutic ERCP between the two groups, the estimated sample size was 40 patients per arm. The power of the test was 0.8 . Additionally, $\alpha$ was set to 0.05 for all comparisons. Results were expressed as mean \pm standard deviation (SD) or percentage $(\%)$, when appropriate. Comparisons between the two groups were compared by using $\chi^{2}$ tests (for categorical variables), $\chi^{2}$ tests for trend (for ordinal variables), and twosample independent $t$-tests (for continuous variables). The statistical software package SPSS (v 11; SPSS Inc, Chicago, IL) was used to analyze the data. A significance level of 5\% was used throughout the study.

\section{Results}

Table 1 summarizes the clinical characteristics of all the patients (43 patients in group $\mathrm{C}$ and 42 patients in group $\mathrm{P}$ ). The mean age in group $\mathrm{C}$ was $59.3 \pm 13.0$ years and the mean age in group $P$ was $59.8 \pm 16.6$ years. There were no significant differences between the two treatment groups with respect to patient age, sex, weight, height,
Table I Characteristics of patients, duration, indications, and interventions of procedure (mean, SD, and percentage)

\begin{tabular}{|c|c|c|c|}
\hline & $\begin{array}{l}\text { Group Ca } \\
(n=43)\end{array}$ & $\begin{array}{l}\text { Group } P^{b} \\
(n=42)\end{array}$ & $P$ value \\
\hline Age (years) (mean, SD) & $59.3(13.0)$ & $59.8(16.6)$ & 0.099 \\
\hline \multicolumn{4}{|l|}{ Sex $(\%)$} \\
\hline Male & $18(41.9)$ & $21(50.0)$ & 0.451 \\
\hline Female & $25(58.1)$ & $21(50.0)$ & \\
\hline Weight (kg) (mean, SD) & $55.7($ (II.5) & $56.4(12.8)$ & 0.296 \\
\hline Height $(\mathrm{cm})$ (mean, SD) & $158.0(8.2)$ & $157.3(7.7)$ & 0.690 \\
\hline \multicolumn{4}{|c|}{ American Society of Anesthesiologists physical status (\%) } \\
\hline 1 & II (25.6) & $12(28.6)$ & 0.228 \\
\hline II & $28(65.1)$ & $21(50.0)$ & \\
\hline III & $4(9.3)$ & $9(21.4)$ & \\
\hline $\begin{array}{l}\text { Duration of procedure } \\
\text { (minutes) (mean, SD) }\end{array}$ & $36.2(12.3)$ & $29.2(11.5)$ & 0.089 \\
\hline Indication (\%) & & & 0.629 \\
\hline Cholelithiasis & $17(39.5)$ & $21(50.0)$ & \\
\hline \multicolumn{4}{|l|}{ Hepatobiliary stricture } \\
\hline Malignancy & I8 (4I.9) & $12(28.6)$ & \\
\hline Benign & $4(9.3)$ & $3(7.1)$ & \\
\hline Others & $4(9.3)$ & $6(14.3)$ & \\
\hline Intervention (\%) & & & 0.302 \\
\hline Stone removal & II (25.6) & $17(40.5)$ & \\
\hline Stent insertion and/or removal & $19(44.2)$ & $14(33.3)$ & \\
\hline Explore common bile duct & $4(9.3)$ & $4(9.5)$ & \\
\hline Others & $9(20.9)$ & $7(16.7)$ & \\
\hline
\end{tabular}

Notes: aGroup C: normal saline; broup P: parecoxib. Abbreviation: SD, standard deviation.

ASA physical status, duration of procedure, indication, and intervention of procedure. All procedures were completed successfully by using the intravenous sedation technique.

Table 2 shows the mean dose of sedative and analgesic drugs used during the procedure and post-procedure in the two groups. The mean total dose and dose $/ \mathrm{kg}$ body weight of propofol, midazolam, and fentanyl in both groups were not significantly different. However, the total number of doses of pethidine used during postprocedural period in the parecoxib group was significantly lower than in the control group $(P=0.001)$.

Table 3 demonstrates the pre- and postprocedural VAS score, patient satisfaction, and endoscopist satisfaction in both groups. There were not significant differences in pre-procedural VAS score, pain at 24 hours post-ERCP, or endoscopist satisfaction between the two groups. However, VAS score at 2 and 12 hours post-ERCP in group $\mathrm{C}$ was significantly greater than in group $\mathrm{P}(P=0.005$ and 0.002 , respectively). In addition, patient satisfaction in group $\mathrm{P}$ was significantly higher than in group $\mathrm{C}(P=0.002)$.

Complications during and immediately after ERCP in both groups were not significantly different. However, the incidence of circulatory and respiratory complications 
Table 2 Sedative drugs used during procedure (mean, SD, range) and analgesic drug used post-procedure ( $\mathrm{n}(\%)$ and mean, SD, range)

\begin{tabular}{|c|c|c|c|}
\hline & $\begin{array}{l}\text { Group Ca } \\
(n=43)\end{array}$ & $\begin{array}{l}\text { Group } P^{b} \\
(n=42)\end{array}$ & $P$ value \\
\hline \multicolumn{4}{|l|}{ During procedure } \\
\hline Mean dose of propofol & & & 0.251 \\
\hline Dose/body weight & $3.87(2.12)$ & $3.73(1.44)$ & \\
\hline$(\mathrm{mg} / \mathrm{kg})$ & $0.65-8.33$ & $2.03-9.05$ & \\
\hline Mean dose of midazolam & & & 0.325 \\
\hline Dose/body weight & $0.03(0.01)$ & $0.03(0.01)$ & \\
\hline$(\mathrm{mg} / \mathrm{kg})$ & $0.01-0.05$ & $0.01-0.06$ & \\
\hline Mean dose of fentanyl & & & 0.234 \\
\hline Dose/body weight & $0.001(0.000)$ & $0.001(0.000)$ & \\
\hline$(\mathrm{mg} / \mathrm{kg})$ & $0.000-0.002$ & $0.00 \mathrm{I}-0.002$ & \\
\hline \multicolumn{4}{|l|}{ Postprocedure } \\
\hline \multicolumn{4}{|l|}{ Pethidine used } \\
\hline Total number of patients (\%) & $24(55.8)$ & $9(21.4)$ & $0.001 *$ \\
\hline Mean dose of pethidine & & & 0.119 \\
\hline Dose/body weight & $\mathrm{I} .07(0.70)$ & $0.96(0.28)$ & \\
\hline$(\mathrm{mg} / \mathrm{kg})$ & $0.35-3.13$ & $0.67-1.53$ & \\
\hline
\end{tabular}

Notes: ${ }^{\mathrm{a} G r o u p ~ C: ~ n o r m a l ~ s a l i n e ; ~ b r o u p ~ P: ~ p a r e c o x i b ; ~}{ }^{*}$ considered to be of statistical significance.

Abbreviation: SD, standard deviation.

in group $\mathrm{C}$ was higher than group P. Hypotension was the most common adverse event in the two groups (Table 4).

\section{Discussion}

The present clinical study was designed to evaluate the analgesic efficacy of preprocedural parecoxib on post-therapeutic ERCP pain. Our results demonstrated that preprocedure administration of parecoxib was clinically effective for ERCP patients. Pain during the first 12 hours post-ERCP

Table 3 Pre-and postprocedural pain (mean, SD) and patient and endoscopist satisfaction (n, \%)

\begin{tabular}{|c|c|c|c|}
\hline & $\begin{array}{l}\text { Group Ca } \\
(n=43)\end{array}$ & $\begin{array}{l}\text { Group Pb } \\
(n=42)\end{array}$ & $P$ value \\
\hline Preprocedural pain (VAS) & $0.79(0.99)$ & $0.60(0.89)$ & 0.592 \\
\hline \multicolumn{4}{|c|}{ Postprocedural pain (VAS) } \\
\hline 2 hours & $3.09(2.68)$ & $0.8 \mathrm{I}(1.55)$ & $0.005^{*}$ \\
\hline 12 hours & $\mathrm{I} .8 \mathrm{I}(\mathrm{I} .72)$ & $0.74(1.34)$ & $0.002 *$ \\
\hline 24 hours & $\mathrm{I} .05(2.0 \mathrm{I})$ & $0.48(1.13)$ & 0.362 \\
\hline Patient satisfaction & & & $0.002 *$ \\
\hline Very satisfied & 15 (34.9) & $32(76.2)$ & \\
\hline Satisfied & $20(46.5)$ & $8(19.0)$ & \\
\hline Neutral & $7(16.3)$ & $2(4.8)$ & \\
\hline Unsatisfied & $\mathrm{I}(2.3)$ & 0 & \\
\hline Endoscopist satisfaction & & & 0.953 \\
\hline Very satisfied & $16(37.2)$ & $15(35.7)$ & \\
\hline Satisfied & $15(34.9)$ & $16(38.1)$ & \\
\hline Neutral & $12(27.9)$ & II (26.2) & \\
\hline Unsatisfied & 0 & 0 & \\
\hline
\end{tabular}

Notes: ${ }^{\mathrm{a} G r o u p ~ C: ~ n o r m a l ~ s a l i n e ; ~ b r o u p ~ P: ~ p a r e c o x i b ; ~}{ }^{*}$ considered to be of statistical significance. VAS $0-10(0=$ none and $10=$ unbearable $)$.

Abbreviations: SD, standard deviation; VAS, visual analog scale.
Table 4 Complications during and immediately after ERCP (n, \%)

\begin{tabular}{llll}
\hline & $\begin{array}{l}\text { Group } \mathbf{C}^{\mathbf{a}} \\
(\mathbf{n}=\mathbf{4 3})\end{array}$ & $\begin{array}{l}\mathbf{G r o u p ~}^{\mathrm{b}} \\
\mathbf{( n = 4 2 )}\end{array}$ & $\mathbf{P}^{\text {value }}$ \\
\hline Overall & $33(76.7)$ & $25(59.5)$ & 0.088 \\
Cardiovascular-related & $28(65 . \mathrm{I})$ & $2 \mathrm{I}(50.0)$ & 0.158 \\
Hypotension & $24(55.8)$ & $20(47.6)$ & 0.450 \\
Bradycardia & $3(7.0)$ & $\mathrm{I}(2.4)$ & 0.317 \\
Arrhythmia & $\mathrm{I}(2.3)$ & 0 & 0.320 \\
Respiratory-related & $5(\mathrm{II} .6)$ & $3(7.1)$ & 0.479 \\
Hypoxia $\left(\mathrm{SpO}_{2}<90 \%\right)$ & $\mathrm{I}(2.3)$ & 0 & 0.320 \\
Upper airway obstruction & $4(9.3)$ & $3(7.1)$ & 0.717 \\
Procedure-related & 0 & $\mathrm{I}(2.4)$ & 0.309 \\
Pancreatitis & 0 & $\mathrm{I}(2.4)$ & 0.309 \\
\hline
\end{tabular}

Notes: aGroup C: normal saline; bgroup P: parecoxib.

Abbreviation: ERCP, endoscopic retrograde cholangiopancreatography.

in the parecoxib group was significantly lower than in the placebo group. In addition, patient satisfaction in the parecoxib group was also significantly higher than in the placebo group. Many previous studies demonstrated the analgesic efficacy of a single dose of parecoxib in the management of acute postoperative pain. ${ }^{13,14}$ However, pain is complex and subjective, and attempts to make valid assessments of it have been fraught with difficulties. It is also influenced by numerous intrinsic and extrinsic factors, and the multiple aspects of pain have been assessed in many different ways.

Measurement of pain relies on patient self-report or on the inferences physicians make on the basis of patient behavior. Pain, however, is likely to vary over time and with different activities. ${ }^{15}$ The VAS score is widely used in the measurement of pain since it is simple to use and provides a sensitive indication of pain intensity. ${ }^{16}$ The differences in score measured at two different times or by two different patients are referenced to categorical responses contrasting the two health states in order to determine clinically meaningful differences.

Acute pain is a normal physiologic response to an adverse thermal, chemical, or mechanical stimulus that may be caused by surgery, trauma, or acute illness. ${ }^{5}$ Postprocedural pain is managed with the use of NSAIDs, opioids, and local anesthetics. Opioid therapy is recommended as the first choice of medication for the management of postprocedural pain but is associated with a number of adverse effects. ${ }^{17}$ Conventional NSAIDs have been used in the management of various types of acute and chronic pain. However, the traditional NSAIDs are generally contraindicated in acute traumatic and surgical pain owing to inhibition of platelets and bleeding potential. Systematic reviews suggest that COX-2 inhibitors are an effective treatment for acute postprocedural pain. ${ }^{18-20}$ 
COX-2 inhibitors are well tolerated when used for preoperative pain management. Because platelets do not contain COX-2, all synthesis of thromboxane A2 in the platelet is mediated by COX-1. Parecoxib is the prodrug of valdecoxib, a selective COX-2 inhibitor, developed for parenteral administration. It exerts its analgesic effect through several proposed mechanisms.

The analgesic efficacy of parecoxib in comparison with a placebo demonstrated a greater analgesic effect with parecoxib. This finding is not unexpected because the analgesic effect of the standard dose $(40 \mathrm{mg}$ ) of parecoxib is understood to be an action. Nonetheless, the data are helpful to some degree in understanding the potency of parecoxib in managing post-ERCP pain. The timing of the use of parecoxib has received considerable attention based on the research models. The impact of constitutively produced central nervous system (CNS) COX-2 on pain perception is also being considered. ${ }^{21,22}$ The most critical time to prevent the windup phenomenon of the CNS may be before the COX-2 mediated prostaglandins are produced in the CNS.

Parecoxib was well tolerated in this study. Adverse events were uncommon. Importantly, no evidence of serious adverse events, such as bleeding, was seen with the parecoxib. Additionally, the incidence of adverse events was similar among the two groups. The adverse events in both groups in the present study occurred due to the sedative agents used. For procedure-related complications, the previous studies showed that, acute pancreatitis developed in $1.3 \%$ to $24.4 \%$ of patients undergoing ERCP. ${ }^{23,24}$ Many factors including difficult cannulation, coagulation current used during sphincterotomy, and repeated injections of contrast into the pancreatic duct and sphincter of Oddi dysfunction, possibly increase the risk of post-ERCP pancreatitis. In the present study, the patient-related factors, baseline clinical presentation, severity of disease, and procedural interventions were similar in both groups. There were no signs and symptoms of post-ERCP pancreatitis in group C. Although, one patient in group $\mathrm{P}$ developed acute pancreatitis, the mean pain score in this group was not significantly higher than in group C.

The current study did not compare the cost effectiveness between the two groups. Indirectly, the result of the study showed that the total number of doses of rescue medication used after the procedure in group $\mathrm{P}$ was lower than in group $\mathrm{C}$. If so, the cost of the rescue medication in group $\mathrm{P}$ was also lower.

Our study has several limitations. First, we use VAS score for pain assessment. The large variability around the mean and the discordance of this scale may reflect a problem with the reproducibility or reliability of our results.
We are unable to find any published studies of the reproducibility of measurement of acute pain in the ERCP patients. Second, in our practice, we do not routinely measure serum amylase and lipase levels after the procedure. Abdominal pain from post-ERCP pancreatitis can affect the VAS score. However, during postprocedural period, the patients who develop abdominal pain and fever will be investigated for acute pancreatitis. One patient in group P developed acute pancreatitis as confirmed by clinical and laboratory tests. Third, the pain score assessed in this study was limited to pain intensity and pain rescue medication. There seems to be considerable individual variability in post-ERCP pain perception even following standardized procedure. ${ }^{25}$ The sensitivity to small changes in pain increases the validity of pain measurement, it can be problematic, when using the VAS to compare effectiveness of differences in mean VAS score, to determine when they can be declared statistically significant, even though they may be of little clinical significance to the patient. ${ }^{26}$ Therefore, to advance studies of the efficacy of preprocedure administration of parecoxib for therapeutic ERCP patients, it is important to identify a minimum clinically significant difference in pain that can be used as a criterion for assessing differences between the parecoxib and the placebo effects. Additionally, the future research of a large population is needed to replicate and compare the findings of this current study. Last, there was a long interval time from the assessment to the interpretation of pain score, and the study was limited to early (24 hours) post-ERCP procedure. Extrapolation of these findings to other time periods will be undertaken for new discoveries.

\section{Conclusion}

Preprocedure intravenous administration of a single dose of parecoxib (40 mg) significantly reduced postoperative pain in patients who had undergone an ERCP procedure. The analgesic efficacy of a standard dose of parecoxib was clearly demonstrated during the first 12 hours postprocedure. Additionally, patient satisfaction in the parecoxib group was also higher than in the control group.

\section{Disclosure}

The authors report no conflicts of interest in this work.

\section{References}

1. Bromley L. Pre-emptive analgesia and protective premedication. What is the difference? Biomed Pharmacother. 2006;60(7):336-340.

2. Amornyotin S, Phasurin T, Wongnuch P. Pain score within twenty-four hours post endoscopic retrograde cholangiopancreatography: a comparison between diagnostic and therapeutic procedures. Gastroenterology Insights. 2009; 1:e7. 
3. Adler DG, Baron TH, Davila RE, et al. ASGE guideline: the role of ERCP in diseases of the biliary tract and the pancreas. Gastrointest Endosc. 2005;62(1):1-8.

4. Hawes RH. Diagnostic and therapeutic uses of ERCP in pancreatic and biliary tract malignancies. Gastrointest Endosc. 2002;56(Suppl 6): S201-S205.

5. Carr DB, Goudas LC. Acute pain. Lancet. 1999;353(9169): 2051-2058.

6. Fosslien E. Adverse effects of nonsteroidal anti-inflammatory drugs on the gastrointestinal system. Ann Clin Lab Sci. 1998;28(2):67-81.

7. Pertusi RM. Selectively cyclooxygenase inhibition in pain management. J Am Osteopath Assoc. 2004;104(11 Suppl 8):S19-S24.

8. Cheer SM, Goa KL. Parecoxib (parecoxib sodium). Drugs. 2011;61(8): 1133-1141.

9. Barton SF, Langeland FF, Snabes MC, et al. Efficacy and safety of intravenous parecoxib sodium in relieving acute postoperative pain following gynecological laparotomy surgery. Anesthesiology. 2002;97(2):306-314.

10. Riest G, Peters J, Weiss M, et al. Preventive effects of perioperative parecoxib on post-discectomy pain. Br J Anaesth. 2008;100(2):256-262.

11. American Society of Anesthesiologists Task Force on Sedation and Analgesia by Non-Anesthesiologists. Practice guidelines for sedation and analgesia by non-anesthesiologists. Anesthesiology. 2002;96(4):1004-1017.

12. Amornyotin S, Chalayonnawin W, Kongphlay S. Deep sedation for endoscopic retrograde cholangiopancreatography: a comparison between clinical assessment and Narcotrend ${ }^{\mathrm{TM}}$ monitoring. Med Devices (Auckl). 2011;4:43-49.

13. Mehlisch DR, Desjardins PJ, Daniels S, Hubbard RC. Single doses of parecoxib sodium intravenously are as effective as ketorolac in reducing pain after oral surgery. J Oral Maxillofac Surg. 2003; 61(9):1030-1037.

14. Bikhazi GB, Snabes MC, Bajwa ZH, et al. A clinical trial demonstrates the analgesic activity of intravenous parecoxib sodium compared with ketorolac or morphine after gynecologic surgery with laparotomy. Am J Obstet Gynecol. 2004;191(4):1183-1191.

15. Turk DC, Okifuji A. Assessment of patients' reporting of pain: an integrated perspective. Lancet. 1999;353(9166):1784-1788.
16. Briggs M, Closs JS. A descriptive study of the use of visual analogue scales and verbal rating scales for the assessment of postoperative pain in orthopedic patients. J Pain Symptom Manage. 1999;18(6):438-446.

17. Marret E, Kurdi O, Zufferrey P, Bonnet F. Effect of nonsteroidal antiinflammatory drugs on patients-controlled analgesia morphine side effects: meta-analysis of randomized controlled trials. Anesthesiology. 2005;102(6):1249-1260.

18. Chen LC, Elliott RA, Ashcroft DM. Systematic review of the analgesic efficacy and tolerability of COX-2 inhibitors in post-operative pain control. J Clin Pharm Ther. 2004;29(3):215-229.

19. Straube S, Derry S, McQuay HJ, Moore RA. Effect of preoperative Cox-II-selective NSAIDs (coxibs) on postoperative outcomes: a systematic review of randomized studies. Acta Anaesthesiol Scand. 2005;49(5):601-613.

20. Desjardins PJ,GrossmanEH,Kuss ME, etal. The injectable cyclooxygenase2-specific inhibitor parecoxib sodium has analgesic efficacy when administered preoperatively. Anesth Analg. 2001;93(3):721-727.

21. Ghilardi JR, Svensson CI, Rogers SD, Yaksh TL, Mantyh PW. Constitutive spinal cyclooxygenase-2 participates in the initiation of tissue injuryinduced hyperalgesia. J Neurosci. 2004;24(11):2727-2732.

22. Yaksh TL, Dirig DM, Conway CM, Svenssen CI, Lou ZD, Isakson PC. The acute antihyperalgesic action of nonsteroidal, anti-inflammatory drugs and release of spinal prostaglandin E2 is mediated by the inhibition of constitutive spinal cyclooxygenase-2 (COX-2) but not COX-1. J Neurosci. 2001;21(16):5847-5853.

23. Masci E, Mariani A, Curioni S, Testoni PA. Risk factors for pancreatitis following endoscopic retrograde cholangiopancreatography: a metaanalysis. Endoscopy. 2003;35(10):830-834.

24. Mallery JS, Baron TH, Dominitz JA, et al. Complications of ERCP. Gastrointest Endosc. 2003;57(6):633-638.

25. Werner MU, Mjöbo HN, Nielsen PR, Rudin A. Prediction of postoperative pain: a systematic review of predictive experimental pain studies. Anesthesiology. 2010;112(6):1494-1502.

26. Gallagher EJ, Liebman M, Bijur PE. Prospective validation of clinically important changes in pain severity measured on a visual analog scale. Ann Emerg Med. 2001;38(6):633-638.
Journal of Pain Research

\section{Publish your work in this journal}

The Journal of Pain Research is an international, peer-reviewed, open access, online journal that welcomes laboratory and clinical findings in the fields of pain research and the prevention and management of pain. Original research, reviews, symposium reports, hypothesis formation and commentaries are all considered for publication.

\section{Dovepress}

The manuscript management system is completely online and includes a very quick and fair peer-review system, which is all easy to use. Visit http://www.dovepress.com/testimonials.php to read real quotes from published authors. 